\title{
Flavonoids: An alternative pathway for the treatment of Alzheimer's disease
}

\author{
Paramita Das», K. Preethi, A. Angelin Kiruba, K. Nikhil and Anjali Nayak \\ Department of Pharmacy, Krupanidhi College of Pharmacy, Chikkabellandur, Carmelaram Post, Varthur, Bangalore-560035, Karnataka,
} India

\section{Article Info}

Article history

Received 20 August 2021

Revised 6 October 2021

Accepted 7 October 2021

Published Online 30 December 2021

\section{Keywords}

Alzheimer's

Antioxidant

Dementia

Flavonoids

Tau-phosphorylation

\begin{abstract}
Alzheimer's is a non-curative disease that occurs in most of the geriatric patients worldwide. It is one of the top 10 diseases which lead to mortality. According to Indian statistics 2020, the average age for symptoms to occur in Alzheimer's is 66-68 years. Patients can survive up to 8 years after the symptoms of dementia. Women are predominant than men. As there is no permanent treatment for Alzheimer's, but medication and management strategies may temporarily improve. On the basis of clinical trials, it can be suggested that single herbs may offer complementary benefits to the approved drugs. Flavonoids are used prophylactically to treat Alzheimer's, as flavonoids are present in most of the fruits, vegetables, and other daily essential products like apple, berries, spinach, red cabbage, onion, dark chocolate, green tea, etc. Flavonoids are also used to treat early symptoms of Alzheimer's like learning and memory loss as flavonoids cross blood-brain barrier (BBB) and prevent tangles. Natural flavonoids mainly possess antioxidant and neuroprotective action which helps to restore damaged brain cells up to a certain extent. Myricetin, morin. rutin, quercetin, fisetin, ginkgo biloba extract, genistein, kaempferol, apigenin, anthocyanin, glycitein are some of the flavonoids used in prevention of Alzheimer's disease. In present study, we discuss different flavonoids to prevent and treat symptoms that are associated with Alzheimer's disease.
\end{abstract}

\section{Introduction}

Alzheimer's disease (AD) is the neurodegenerative disorder and a most frequent basis of dementia which is more affected in elderly people and provokes alternation in the Cerebrospinal Nervous System (Francesca et al., 2010). Neuropsychiatric symptoms are the main features of Alzheimer's disease (Constantine et al., 2011). Few sources show that $50 \%$ of people above 80 years suffer from this kind of dementia (Elena et al., 2018). Alzheimer's disease is a continuous degradation of certain nerve cells that are responsible for memory and other important functions. The major cause for Alzheimer's disease is protein (amyloid) built up in the brain cell, which leads to formation of plaques (Perry et al., 1980). Presently, three genes responsible for rapid onset of Alzheimer's disease such as Amyloid Precursor Protein (APP), Presenilin-1(PSEN1), Presenilin-2 (PSEN2) (Uddin et al., 2019). It also occurs due to the generation of oxidative strain and free radicals (Roxana et al., 2018). Cholinesterase inhibitors and N-methyl D-aspartate (NMDA) antagonist is the current $\mathrm{AD}$ therapy. Contemporary researches suggest that some flavonoids are effective in treating Alzheimer's disease (Airlodi et al., 2018).

Flavonoid belongs to polyphenols shows outstanding therapeutic properties. Myricetin, morin, rutin, quercetin, fisetin, ginkgo biloba extract, glycitein, genistein, kaempferol, apigenin, anthocyanin, are few of the flavonoids used prophylactically in Alzheimer's disease

Corresponding author: Dr. Paramita Das

Assistant Professor, Department of Pharmacy, Krupanidhi College of Pharmacy, Chikkabellandur, Carmelaram Post, Varthur, Bangalore560035, Karnataka, India

E-mail: paramitadas04@gmail.com

Tel.: +91-9742250412

Copyright (c) 2021 Ukaaz Publications. All rights reserved.

Email: ukaaz@yahoo.com; Website: www.ukaazpublications.com
(Carmona et al., 2020). Flavonoids show its neuroprotective action by inhibiting the development of reactive oxygen species and aggregation of beta-amyloid in PC 12 cells, certain flavonoids show anti-AD effects such as myricetin, latin, fisetin, catechins, quercetin, kaempferol and apigenin. Among that, quercetin shows a significant role in the neuroprotective activity (Judy et al., 2007).

\subsection{History and present status of flavonoids}

It has been centuries that the people have known that the plant possesses biological activity. In 1930, the discovery of vitamin P from orange was made. Later, it was known as rutin in 1938 which was flavonoids (Robert et al., 2001). At present, there are more than 4000 different types of flavonoids that are used for symptomatic treatment in most of the diseases due to their vast health benefit (Shashank et al., 2013).

\subsection{Distribution of plant species and their taxonomy}

There are about 1 million secondary metabolites that are obtained from plants, which play a vital role in defence mechanism in different diseases. It includes about 9000 compounds of flavonoids that are used in treating neurological disorders. Flavonoids are distributed in various ferns, mosses, liverworts, lycophytes, flowering and non-flowering plants; further flavonoids are subgrouped into flavones, flavonols, chalcones, anthocyanins and proantho cyanidans. Flavonoids are absent in hornworts (Keiko et al., 2019). Bioflavonoids are flavonoids with biological activity, which are stored in edible parts of plants mainly in vegetables and fruits. They impart colour to berries and citrus fruits. The different flavonoids used in $\mathrm{AD}$ are described in Table 1 along with geographical sources, taxonomy and their uses (Katarzyna et al., 2017). 
Table 1: Taxonomy of flavonoids

\begin{tabular}{|c|c|c|c|c|c|c|c|}
\hline \multirow[t]{2}{*}{ Source } & \multicolumn{4}{|c|}{ Taxonomy } & \multirow[t]{2}{*}{ Flavonoid } & \multirow{2}{*}{$\begin{array}{l}\text { Geographi- } \\
\text { cal source }\end{array}$} & \multirow[t]{2}{*}{ Uses } \\
\hline & Order & Family & Genus & Species & & & \\
\hline Indian guava & Myrtales & Myrtaceae & Psidiuni & P. guajava & Monn & India & $\begin{array}{l}\text { Antioxidant } \\
\text { Neuroprotective }\end{array}$ \\
\hline Grapes & Vitales & Vitaceae & Vitis & V. vmifera & Quercetin & China & $\begin{array}{l}\text { Antiproliferative } \\
\text { Chemo preventive }\end{array}$ \\
\hline Strawberry & Rosales & Rosaceae & Fragana & $F$ virginiana & Fisetin & $\begin{array}{l}\text { Southern } \\
\text { new } \\
\text { England }\end{array}$ & $\begin{array}{l}\text { Antioxidant } \\
\text { Neuroprotective }\end{array}$ \\
\hline $\begin{array}{l}\text { Chamomile } \\
\text { tea }\end{array}$ & Asterales & Asteraceae & Matricaria & M. chamomilla & Apigenin & Japan & $\begin{array}{l}\text { Antiamyloidogenie } \\
\text { Anxiolytic }\end{array}$ \\
\hline Buckwheat & Caryophyllales & Polygonaceae & Fagopyrum & F. esculentum & Rutin & China & $\begin{array}{l}\text { Antioxidant Fibril } \\
\text { disagregating effect }\end{array}$ \\
\hline Spinach & Caiyophyllaes & Amaranthaccae & Spinacia & S. oleracca & Kaempferol & Italy & $\begin{array}{l}\text { Antioxidant } \\
\text { Anticoagulant }\end{array}$ \\
\hline Lupin & Fabales & Fabaceae & Lupinus & L. abramsu & Genistein & Australia & $\begin{array}{l}\text { Cholinesterase } \\
\text { Inhibitors } \\
\text { Immuno- } \\
\text { suppressant }\end{array}$ \\
\hline Black currant & Saxifragales & Grossulariaceae & Ribes & R. nigrum & Anlhocvanin & Russia & $\begin{array}{l}\text { Antineoplastic } \\
\text { Anti-inflammatory }\end{array}$ \\
\hline Ginkgo leaf & Ginkgoales & Ginkgoaceae & Ginkgo & G. biloba & Ginkgo biloba & China & $\begin{array}{l}\text { Antipsychiatric } \\
\text { Antiageing }\end{array}$ \\
\hline Soybean & Fabales & Fabaceae & Glycine & G. gracilis & Glycitein & United States & $\begin{array}{l}\text { Neuroprotective } \\
\text { Anticoagulant }\end{array}$ \\
\hline
\end{tabular}

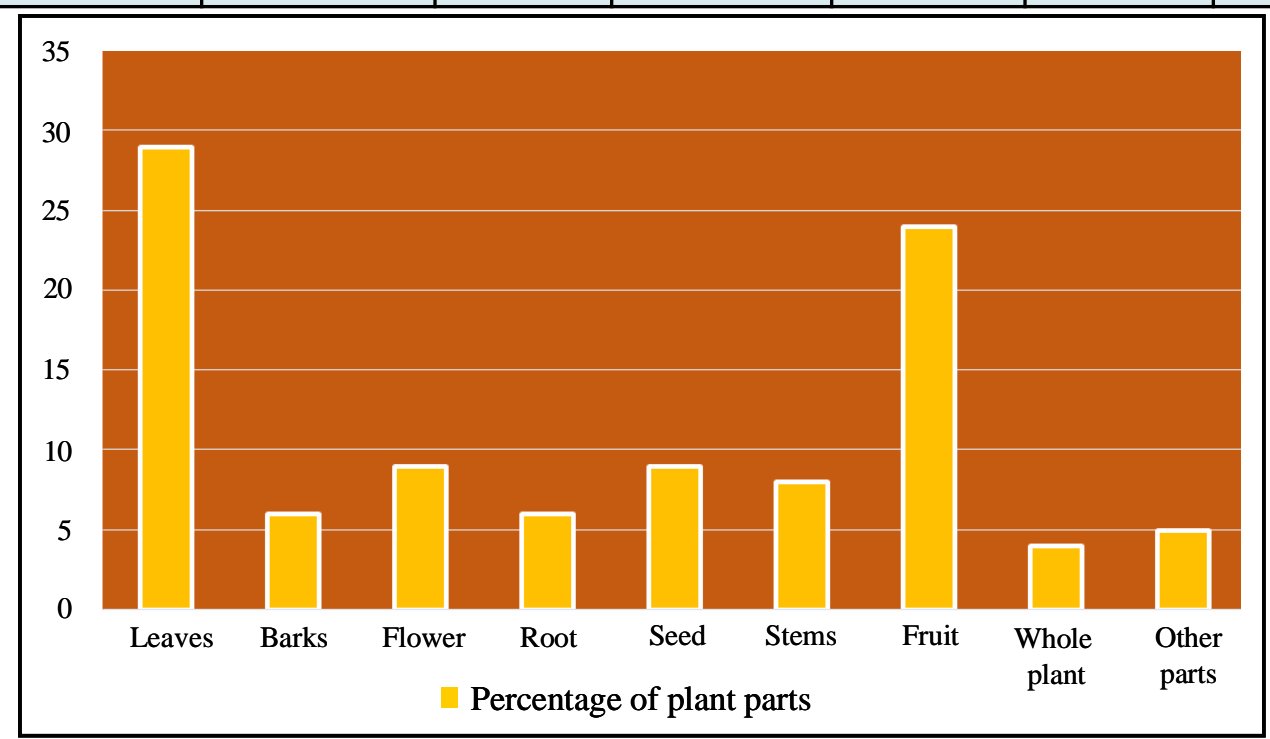

Figure 1: Percentage of plant parts used in Alzheimer's disease.

\section{Methods}

A search of scientific literature and data on recent developments of flavonoids for the treatment of various diseases by using various sources of information available in internet by reviewing scholarly reviews, research articles, magazines, newsletters, thesis, and conference proceedings through search engine such as Google Scholar,
Science Direct, PubMed, Core, Embase, Medline, Medline Plus. PubChem, Scopus, etc.

\section{Biosynthesis of flavonoids}

$\mathrm{P}$ - coumaryl CoA are the substrate derived from phenyl propranoid pathway. It utilizes malonyl CoA (Figure 2 ) and produce naringenin chalcone with the help of chalcone synthase. On further, it undergoes cyclization giving naringenin a major component for producing 
isoflavones (genistein, glycitein), flavones (apigenin, ginkgo biloba) and dihydroflavanol. Dihydroflavonol on reacting with flavonol synthase gives flavonols (morin, quercetin, fisetin, rutin and kaempferol) or on reacting with dihydroflavonol-4-reductase gives leucoanthocyanins. Anthocyanin is formed from leucoanthocyanins with an intermediate anthocyanidins.

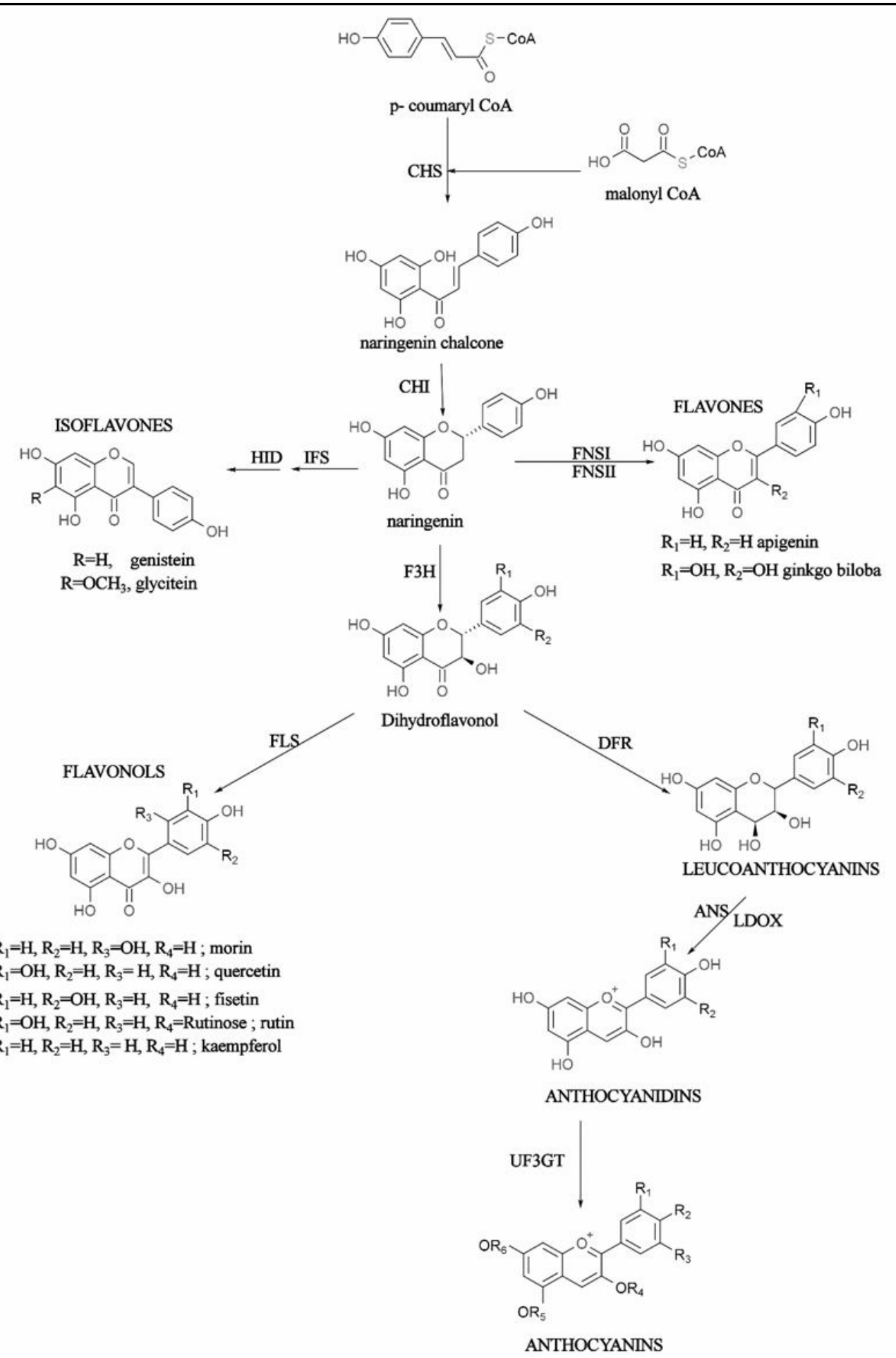

Figure 2: Biosynthesis of flavonoids ANS, anthocyanidin synthase; CHI, chalcone isomcrase; CHR, chalcone reductase; CHS, chajcone synthase; DFR, dihydroflavonol 4-rcductase, F2H, flavanone 2-hydroxylase,F3H, flavanone 3-hydroxylase; FLS, Davonol synthase; FNS, flavone synthase, HID, 2-hydroxyisoflavanone dehydratase; IFS, Isoflavone synthase; LDOX leucoanthocyanidin dioxygenase, UF3GT, UDP glucose flavonoid 3-O-glucosyltransferase. 


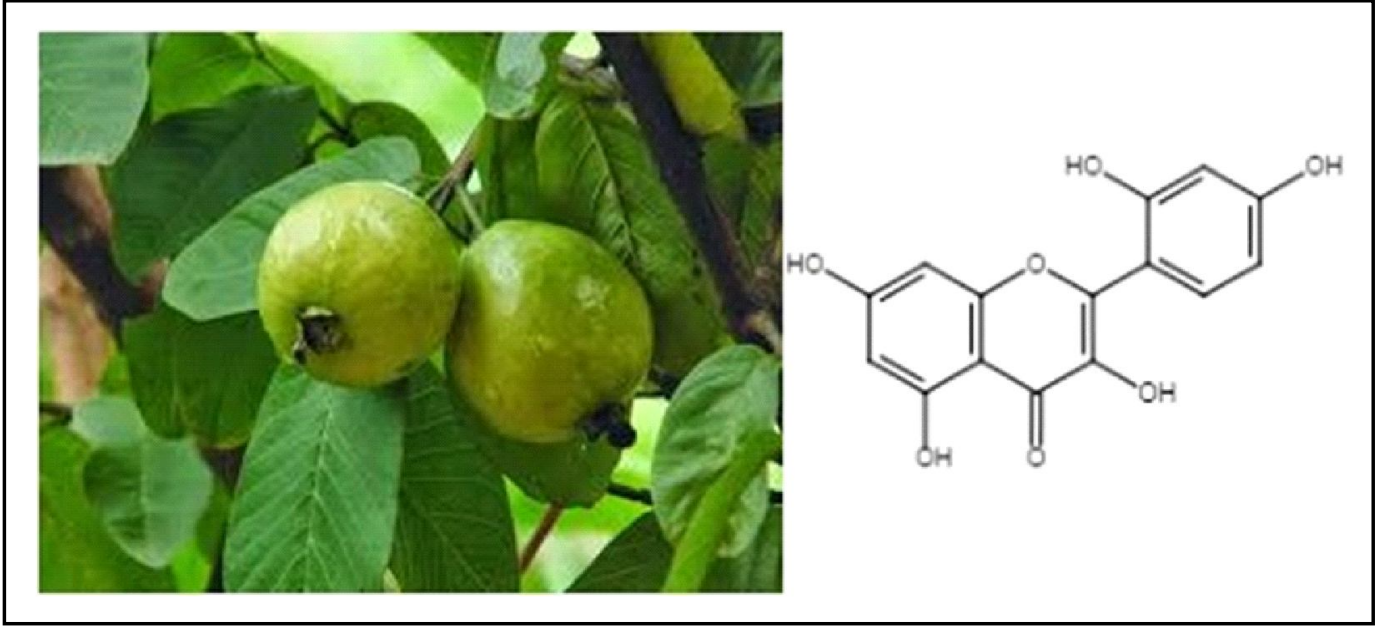

Figure 3: Morin is a main constituent of Psidium guajava.

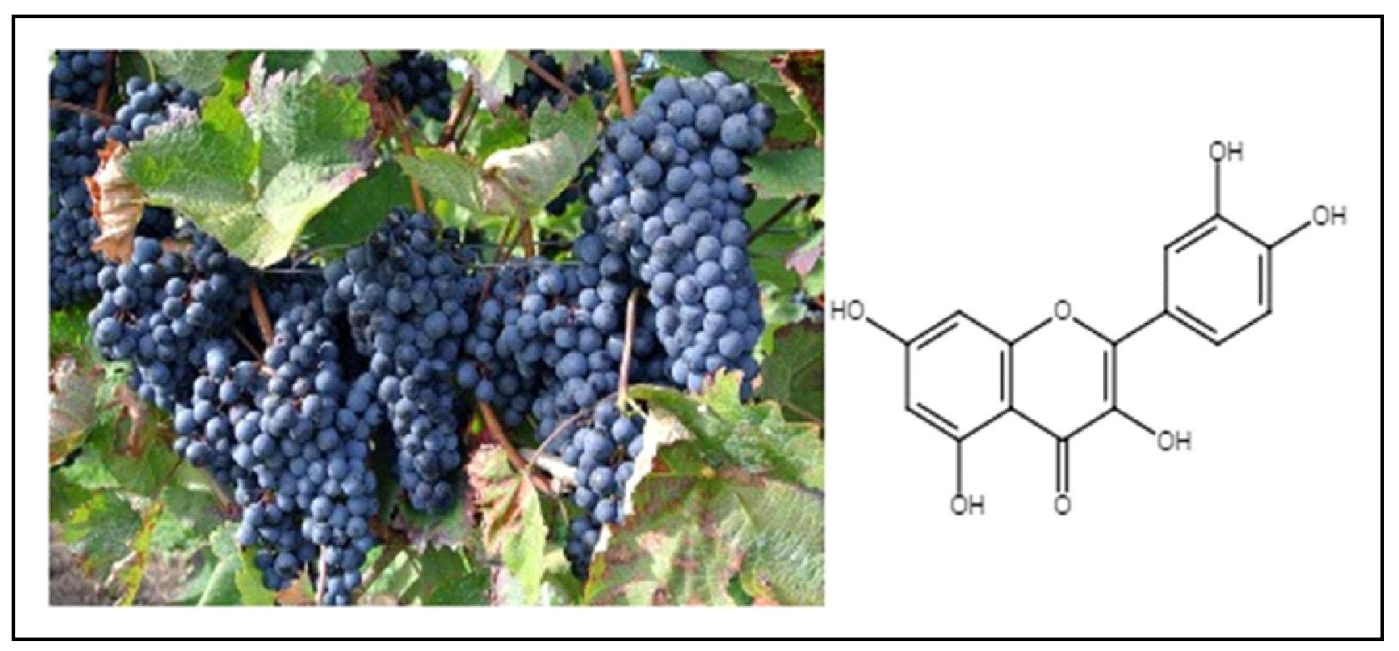

Figure 4: Quercetin is a major constituent of Vitis vinifera.

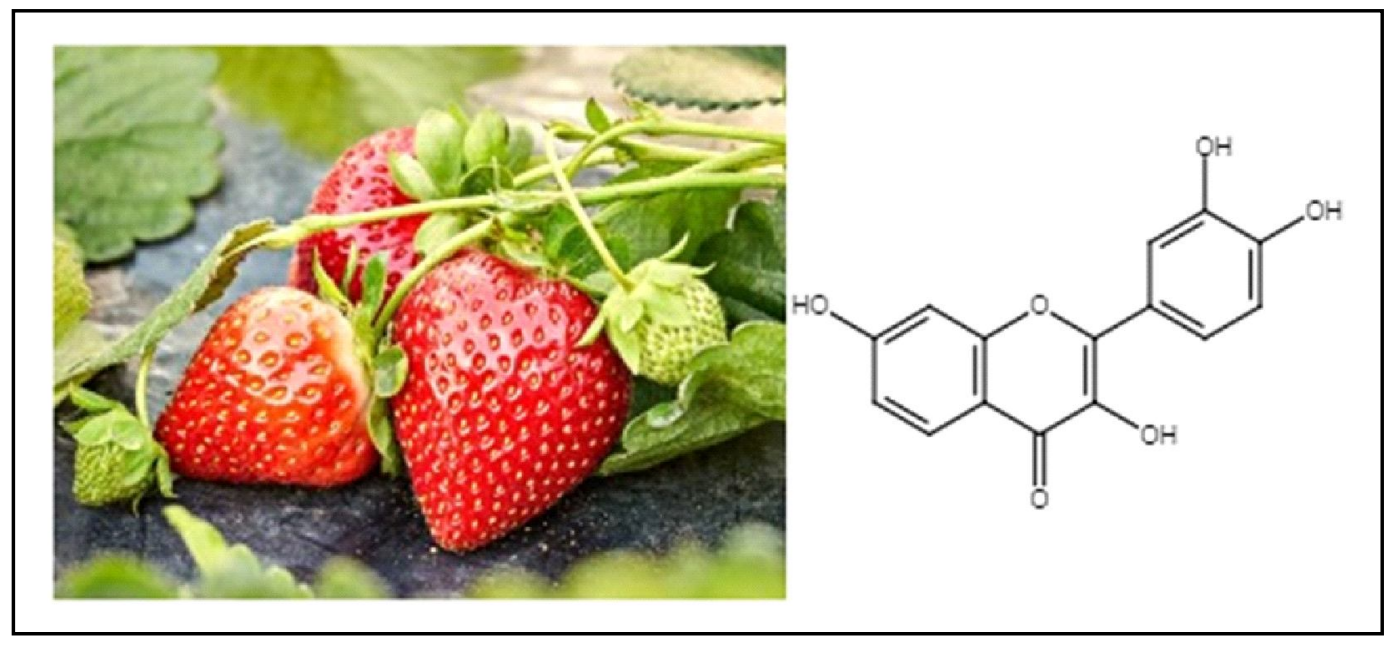

Figure 5: Fisetin is a main constituent of Fragaria virginiana. 


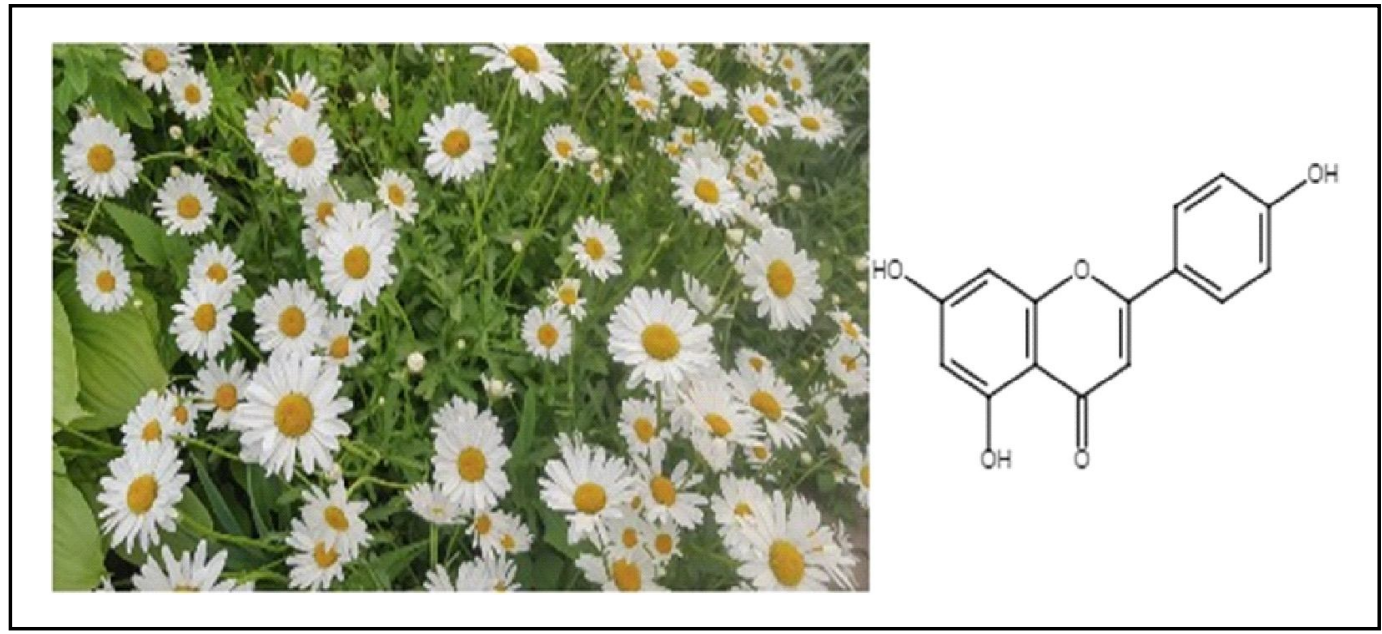

Figure 6: Apigenin is a major constituent of Matricaria chamomilla.

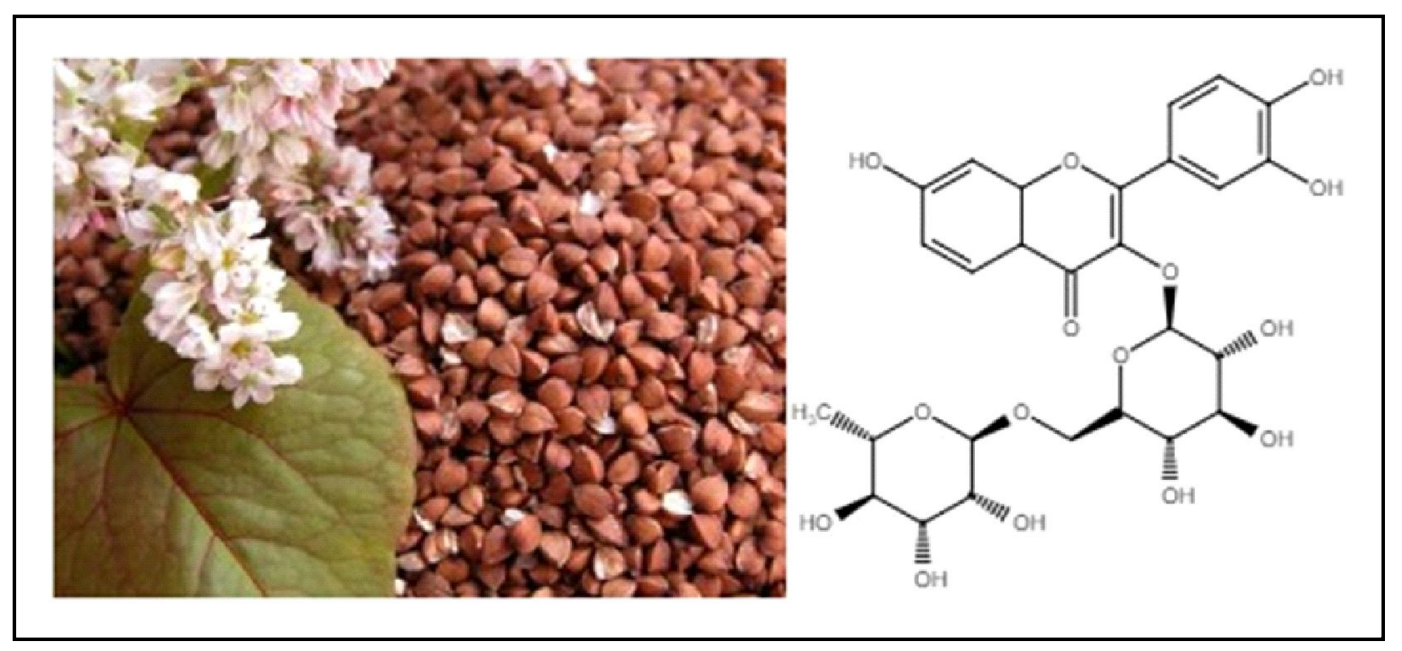

Figure 7: Rutin is a major constituent of Fagopyrum esculentum.

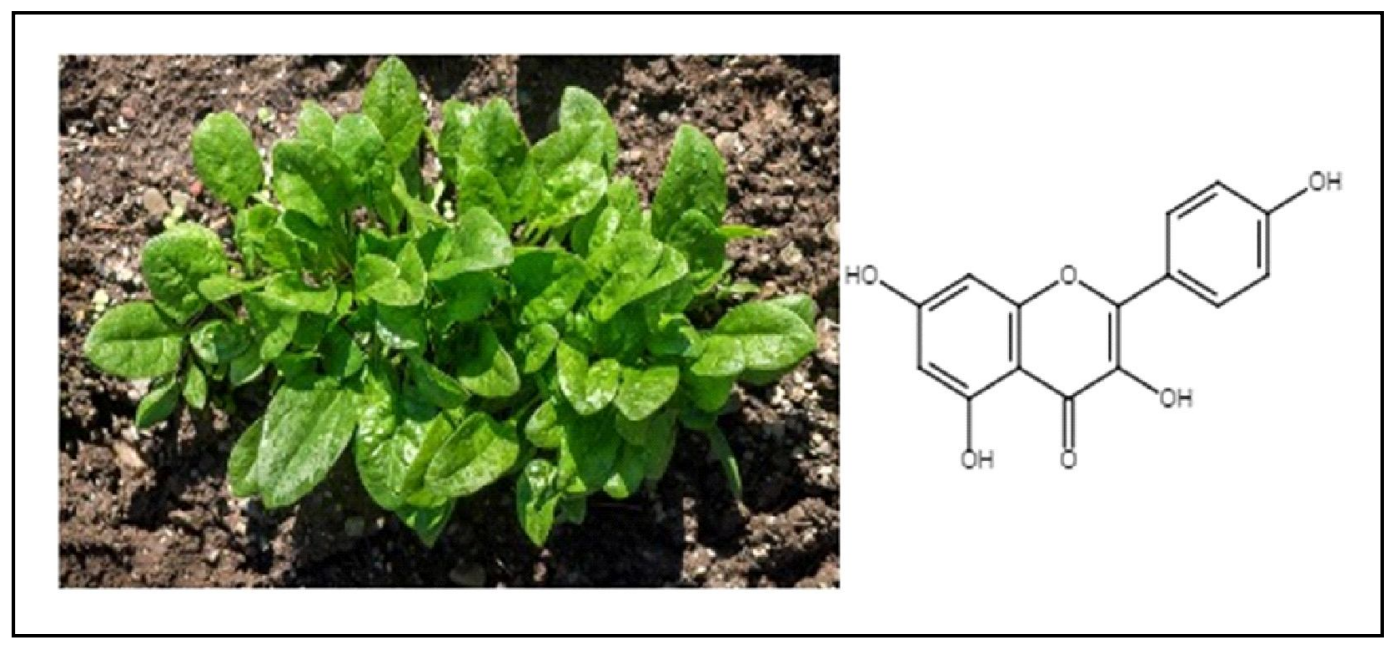

Figure 8: Kaempferol is a major constituent of Spinacia oleracea. 


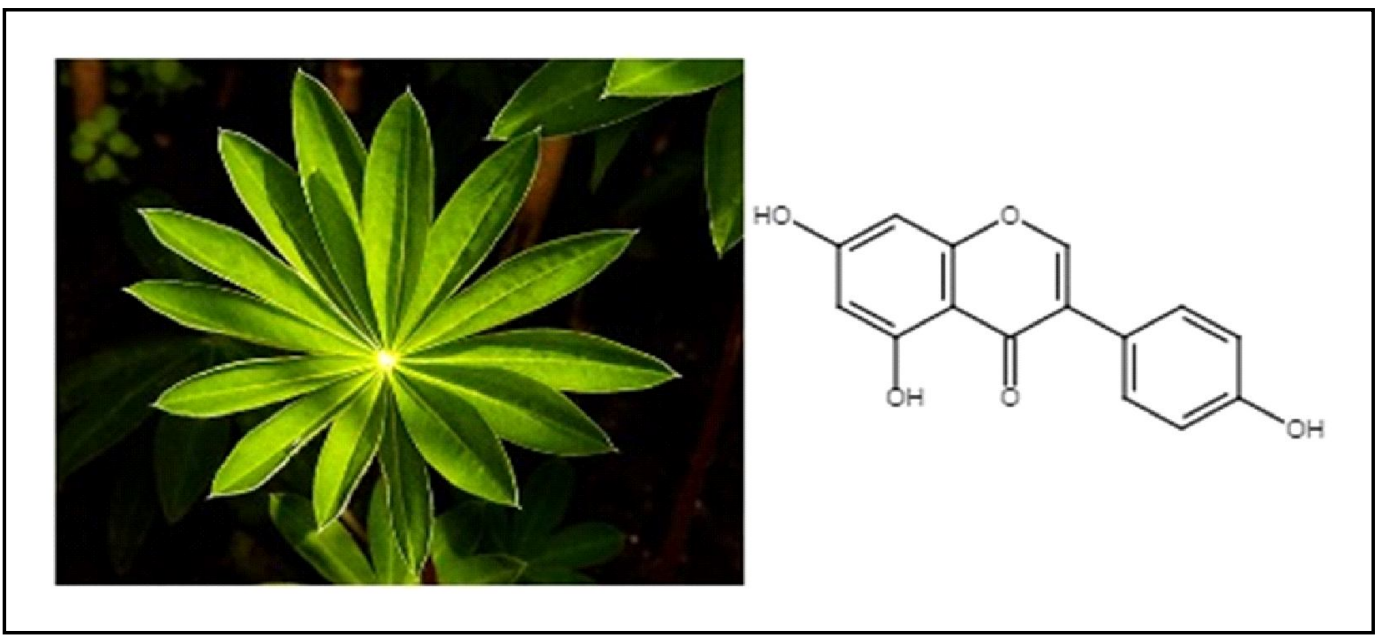

Figure 9: Genistein is a major source of Lupinus abramsii.

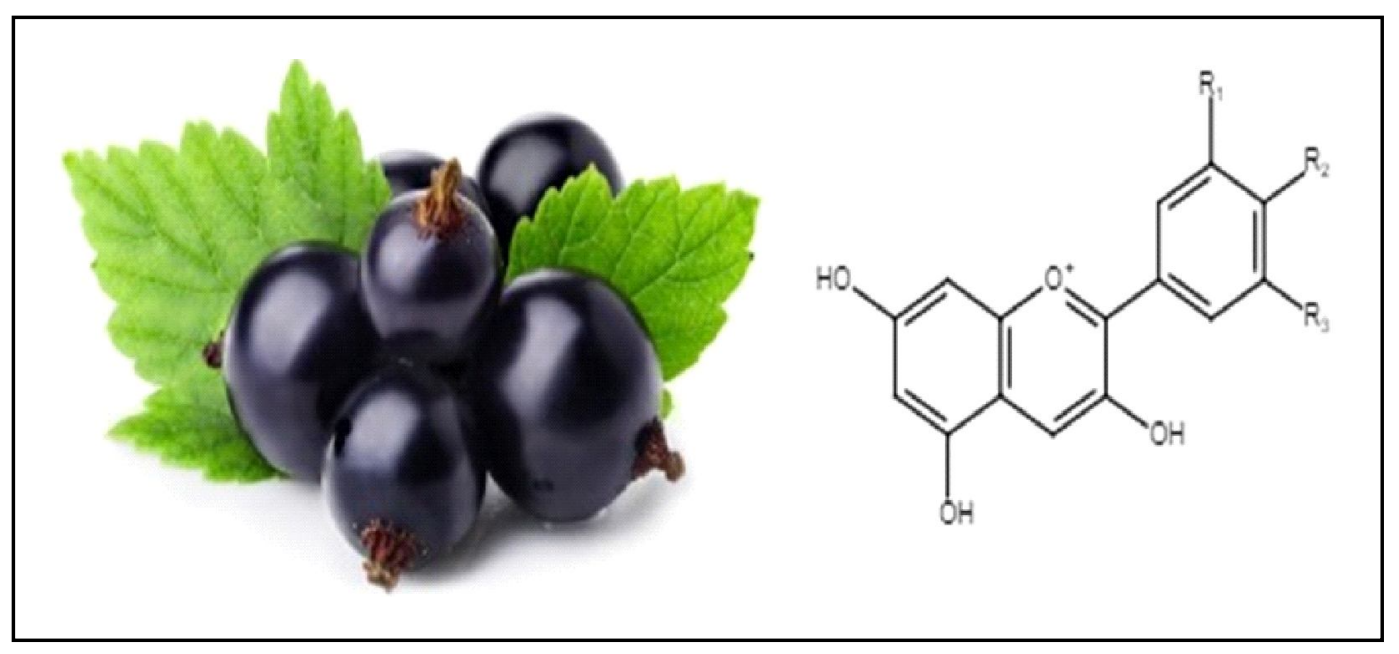

Figure 10: Anthocyanin is a major source of Ribes nigrum.

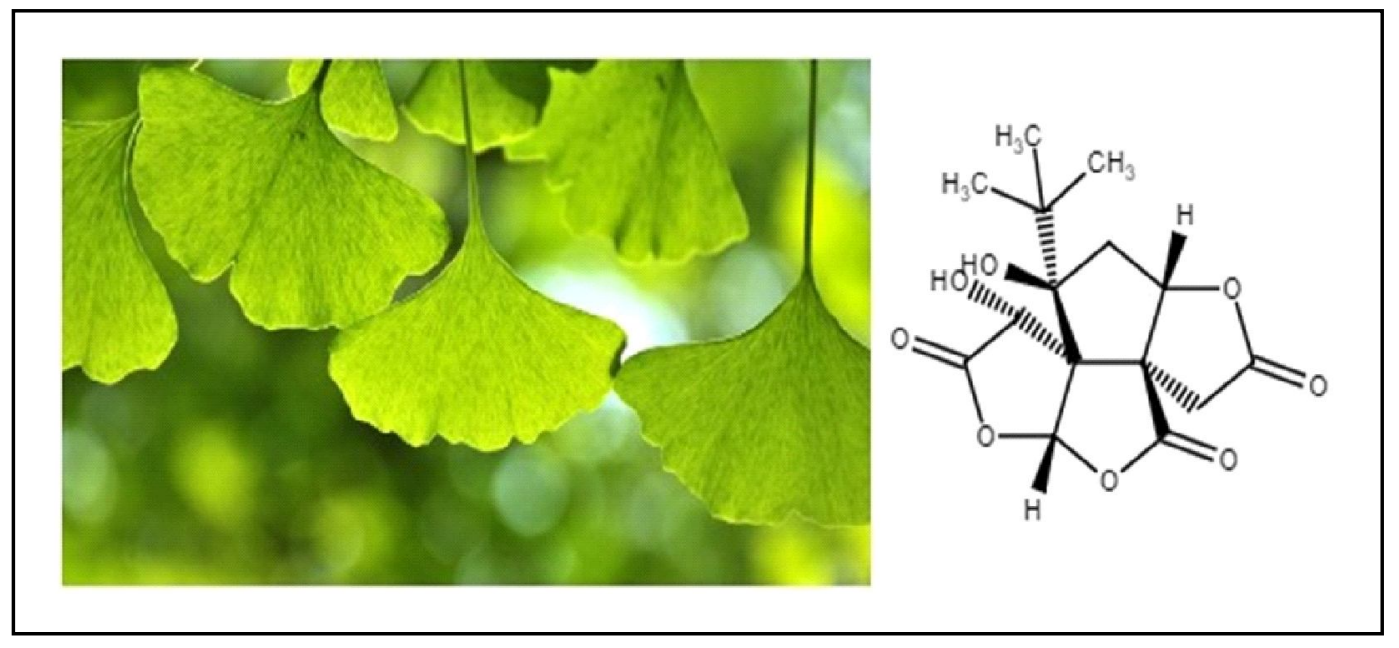

Figure 11: Ginkgo biloba is a major source of Ginkgo biloba. 


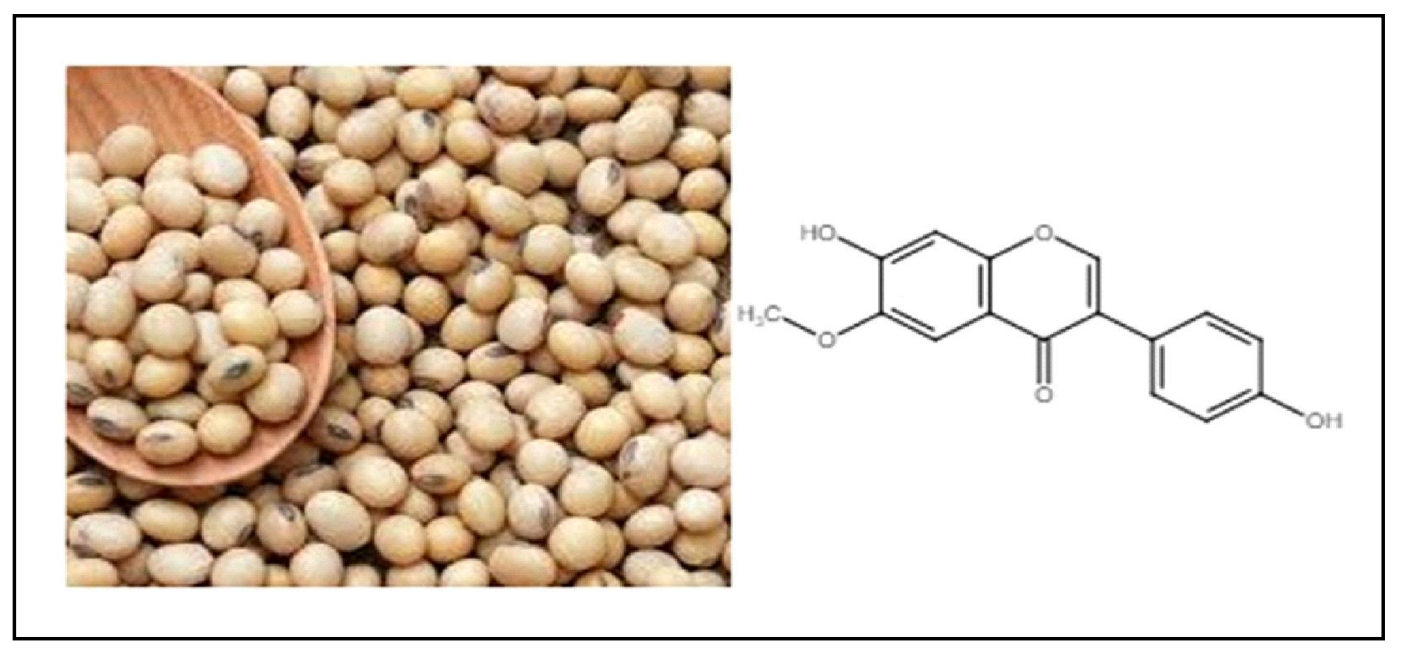

Figure 12: Glycitein is a major source of Glycine gracili.

\section{Flavanoids used against Alzheimer's diseases}

\subsection{Morin}

Morin is yellow color plant-derived natural flavonoids (Moraceae). Almond, fig, and Indian guava contain a high quantity of morin (Choudhury et al., 2017). It exhibits antioxidant, antineoplastic, cardioprotective, antiproliferative, antiamyloidogenic, fibril destabilization, anti-inflammatory, and neuroprotective (Choudhury et al., 2017; Simunkova et al., 2019; Qadeer et al., 2014; Elena et al., 2018). Morin can easily cross the blood-brain barrier (BBB) which aids in the restoration of reminiscence and cerebral functions (a major symptom of $\mathrm{AD}$ ) (Justin et al., 2010). It gets metabolized and finally gets absorbed in the gut as aglycone moiety (Choudhury et al., 2017). The compulsive characteristic of $\mathrm{AD}$ is the poisonous buildup of aggregated $A \beta$ through peptide linkage, which is the resultant of misfolding B hairpin monomer (Gargari et al., 2018). Morin inhibits $\beta$-secretase and $\gamma$-secretase that helps in the prevention of further plaque development in nerve cells (Michal et al., 2005; Etis et al., 2012). In in vivo, morin inhibits GSK-3B, is the major enzyme for determining $\mathrm{AD}$, thereby decreasing the brain levels of phosphorylated Tau (p Tau) (Justin et al., 2010; Yu et al., 2018). Morin acts on p Tau accumulation but does not affect the motor function. Morin has a superior tendency to form $\mathrm{H}$ bonds with the accumulated $A \beta$ at the terminal clusters of the fibrils, that leads to destabilization of $\mathrm{A} \beta$ aggregate (Justin et al., 2010; Simunkova et al., 2019). The antioxidant effect of morin is increased by $\mathrm{Cr}$ (III)-morin complex (Qadeer et al., 2014). Mitochondrial dysfunction and redox homeostasis are the primary cause of $\mathrm{AD}$, this can be reinstated by the consumption of morin (Elena et al., 2018). As an aqueous solubility, morin hydrate has $18 \mu \mathrm{g} / \mathrm{ml}$, where the desired activity is not achieved. Hence, the oral route of micellar is preferred (Sharma et al., 2017). Flavonoids have a greater affinity for metals, the complex formed causes damage to DNA. The more the interaction of flavonoids and metals, the more the antioxidant effect. The complexes include Cd (II) with morin, Zn (II), and Mn (II) with quercetin and other metal-flavonoid complexes which cause programmed cell death (Simunkova et al., 2019).

\subsection{Quercetin}

Quercetin is a flavonol derived from Latin name quercetum which means oak forest. It is mostly present in the citrus fruits, leafy vegetables, tomatoes, honey, nuts, onions, etc. (Anand et al., 2016; Li et al., 2016). Ginkgo biloba, hypericum perforatum, and Sambucus canadensis are the medicinal botanicals where quercetin is found. Higher concentration of quercetin is found in red onions whereas leaves of green and black tea contain lower concentration of quercetin ( $\mathrm{Li}$ et al., 2016). It is a yellow colour bioflavonoid which acts as antiproliferative, chemopreventive, antioxidant, antitumour, antiallergy, anticancer, antiviral, anti-inflammatory, antiulcer, antihypertensive and immunomodulatory (Anand et al., 2016; Khan et al., 2020; Olajide et al., 2020; Chen et al., 2014). Quercetin in combination with ascorbic acid protects brain cell from oxidative damage, thereby preventing Alzheimer's disease (Geetha et al., 2005). Quercetin crosses BBB same as when compared to rutin. The absorption of quercetin is about 3-17\%. It has high metabolism and rapid elimination ( $\mathrm{Li}$ et al., 2016). Quercetin interferes lipid peroxidation, platelet aggregation and capillary permeability. These are the properties that are useful in reduction of plasma lipid level (Xinjun et al., 2020). Metabolism of quercetin takes place in small intestine, colon, liver and kidney (Li et al., 2016). Quercetin inhibits Tau phosphorylation and $\mathrm{A} \beta$ aggregation that are the main hall mark of AD (Khan et al., 2020). It also guards neuronal cell by decreasing neuroinflammation and oxidative strain (Olajide et al., 2020). Quercetin has toxic effects such as mutagenicity, pro-oxidant activity, mitochondrial toxicity and it inhibits the enzymes involved hormone metabolism (Chen et al., 2014).

\subsection{Fisetin}

Fisetin is a flavonol derivative extracted from vegetables and fruits of about 2-160 $\mu \mathrm{g} / \mathrm{g}$ concentration. Strawberries, apple, persimmon have high concentration whereas cucumber, onion and grapes have a low concentration of fisetin belonging to Anacardiaceae and Fabaceae family (Naghma et al., 2013). They exhibit antioxidant, neuroprotective, anti-inflammatory, anticarcinogenic, antiallergy, antiviral, anti-immunomodulatory, antiangiogenic, antifungal and antiageing properties (Rashid et al., 2019). Fisetin inhibits A $\beta$ protein formation. It helps in promoting cognitive functions and memory 
in AD (Shifeng et al., 2021). Fisetin crosses BBB when administered orally, and it improves synaptic functions in Hippocampus (Wenbin et al., 2018). Fisetin lowers oxidative damage induced by hemeoxygenase-1 (HO-1) and ultraviolet radiation. It inhibits extracellular signal regulated kinase (ERK) which promotes intellectual function in AD (Maher et al., 2020; Wang et al., 2018). Amyloid- $\beta$ aggregation, beta strand formation and Tau production are inhibited by fisetin (Wen-bin et al., 2018). Glutathione is a main antioxidant that is produced in liver, this activity is improved by fisetin. Hepatotoxicity is comparatively less than other flavonoids in fisetin as it enhances protective action in liver. 5-HT and noradrenaline levels are increased in brain by fisetin, these act against AD (Meghana et al., 2016; Manorma et al., 2018). Fisetin is rapidly transformed into sulphate in liver (Meghana et al., 2016).

\subsection{Apigenin}

Apigenin is a flavone derived flavonoid which is found in higher concentration in chamomile tea. Parsley, malabar spinach, dried oregano, celery varieties, artichoke and coriander are the other sources of apigenin. Naturally, apigenin is found in glycosylated form (Minqian et al., 2019; Balez et al., 2016). Apigenin exhibits properties such as antiamyloidogenic, antioxidant, anxiolytic, antiinflammatory, anticarcinogenic, neuroprotective effect, super oxide anion scavenging effect, antiviral, antibacterial, antiparasitic and antifungal (Minqian et al., 2019; Venigalla et al., 2015; Zhao et al., 2013). Apigenin is poorly soluble, to enhance its solubility, it is converted to salt form like potassium salts. The salt form of apigenin helps in crossing blood-brain barrier. Apigenin improves memory, decrease $A \beta$ plague and oxidative strain that are associated to AD. Excited calcium ions are blocked by apigenin in brain cells; these improves neuron signalling which helps in betterment of AD (Balez et al., 2016). Due to decrease in metabolic rate, there is decrease in absorption and excretion of apigenin takes place through bile and urine (Angeline et al., 2005). In mice, 90 days oral dose $(40 \mathrm{mg} / \mathrm{kg} /$ day) of apigenin improved perception and cognitive functions in $\mathrm{AD}$. Usually, apigenin is non-toxic, even in higher doses, it produces muscle relaxant and sedative action (Balez et al., 2016; Zhao et al., 2013).

\subsection{Rutin}

Rutin is sometimes known as sophorin. Rutin is a natural flavonoid, that belongs to flavonol group. Its name originates from the plant Ruta graveolens. It is extracted from plants mainly onions, tea, broccoli, apples, etc. (Isha et al., 2015; Adaze et al., 2018). It exhibits antioxidant, neuroprotective, anti-inflammatory, antiangiogenic, antiallergic, antiviral, antidiabetic, antineoplastic, fibril disaggregating effect, antiamyloidogenic activities (Adaze et al., 2018; Bang et al., 2015; Mostafa et al., 2019). The main drawback of rutin is its poor solubility, so the conversion of rutin to its salt form (sodium rutin) improves its solubility to cross the BBB (blood-brain barrier) and improves bioavailability. Salts of rutin enhance microglial cells in the brain, which clears A $\beta$ plaques and reduces Alzheimer's disease (Rui-yuan et al., 2019). Rutin reduces the ischaemic neural apoptosis by lipid peroxidation and p53 expression with an increase in endogenous antioxidant defence enzyme, this thereby reduces neuroinflammation in Alzheimer's disease (Mahendra et al., 2020). Rutin has higher binding energy with protein when compared with other flavonoids (Raju et al., 2018). Cognitive dysfunction is mainly due to reduced blood flow to the brain in Alzheimer's disease, this is altered by rutin. Rutin undergoes phase- 2 metabolism in the liver. It is available in tablets and capsules, about $4000 \mathrm{mg} /$ day is safe. Rutin is non-toxic up to $5000 \mathrm{mg} / \mathrm{kg}$ therapeutically rutin is not widely used because of its poor absorption, high metabolism, and rapid excretion (Annoni et al., 1986).

\subsection{Kaempferol}

Kaempferol is also called as kaempferide. Its name originates from German naturalist Engelbert Kaempfer. It is flavonol derivative found in plants, vegetable and fruits like tea, sprouts, citrus fruits, grape, cabbage, strawberry, etc., medicinal plants like Ginkgo biloba, Equisetum species, etc. It occurs mostly in glycoside form. Kaempferol is a yellow crystalline powder, that is soluble in organic solvents. It exhibits anti-inflammatory, antioxidant, anti-cancer, neuroprotective, antidiabetic, antihistaminic, analgesic, immunomodulatory, anxiolytic, antiestrogenic, antiosteoporotic, antimicrobial (Rashid et al., 2019; Ren et al., 2019). Kaempferol has low absorption, poor bioavailability and metabolism takes place in intestine and liver by phase- 1 oxidation and phase- 2 glucuronidation. Nanotechnology improves absorption and bioavailability of kaempferol, excretion is usually high and occurs through bile (Barve et al., 2009; Ren et al., 2019). Kaempferol progresses intellectual functions related with $\mathrm{AD}$ by activating intracellular signalling pathway of memory when $10 \mathrm{mg} / \mathrm{kg} /$ day is administered for 21 days (Kouhestani et al., 2018). Various concentration of kaempferol attenuates apoptotic cells percentage and regulates gene expression and proteins (Chen et al., 2013; Zhang et al., 2021). Pathogenesis of AD is delayed owing to kaempferol and other natural antioxidants (Ren et al., 2019). The increased levels of copper in AD are complexed with kaempferol as it possesses pro-oxidant property to form $\mathrm{Cu}$-kaempferol complex that protects brain from free radicals and restores brain function (Simunkova et al., 2021). Kaempferol has low toxicity, but on drugdrug interaction, or on herbal interactions its toxicity increases and therapeutic effect decreases (Chan et al., 2013).

\subsection{Genistein}

Genistein is an isoflavone derived from leguminous family (especially from soybean, fava bean, tofu, lupin and kudzu) (Li et al., 2017; NCBI, 2021). Naringenin produces genistein in plants, which exhibits antitumour, antioxidant, antimigration, metabolism regulation, neuroprotective, anti-inflammatory, antiangiogenic, immunosuppressive, antiacetylcholinesterase, antimicrobial, metal chelating (Li et al., 2017; Uddin et al., 2019; Hong et al., 2019; Baipinget al., 2018). A $\beta$ formation is inhibited by genistein through activation of PKC (protein kinase C) signalling pathway (Uddin $e t$ $a l ., 2019)$. Genistein helps in protection against Tau hyper phosphorylation, ER stress, apoptosis and maintains apolipoprotein E and GSK 3B (glycogen synthase kinase 3 beta) levels. Manganese superoxide dismutase decreases the formation of plague and NFTs by eliminating superoxide free radical that improves cognitive functions associated in AD (Duan et al., 2021). Genistein increases cognitive functions in Alzheimer's disease (Uddin et al., 2019). Genistein acts as an antioxidant which helps in deterrence of $\mathrm{AD}$ by inhibiting pro-oxygenic agents, neuronal necrosis, and influx of intracellular calcium (Duan et al., 2021). Genistein when given orally has poor bioavailability, glycosidic form is partially absorbed and aglycosidic form is well absorbed (Uddin et al., 2019). Genistein 
effectively crosses BBB and neurological status was enhanced (Kloska et al., 2012). Genistein is a potent nontoxic drug at smaller doses used widely in treatment of AD (Hong et al., 2019).

\subsection{Anthocyanin}

Anthocyanin is a flavonol derived pigment which imparts colour to the plant (flowers, fruits and vegetables) (Jessie et al., 2014). Anthocyanin is water soluble and more than 600 types of anthocyanin are identified (Tarun et al., 2020). These are responsible for the colours; for instance blue, purple and red (Khoo et al., 2017). The main source of anthocyanin is such as berries, grapes, tubers, red cabbage and black current. It exhibits antioxidant, scavengers of ROS, anti-inflammatory, anticancer, immuno protective, antimutagenic, antimicrobial, antidiabetic, antineurodegerative and reduces alopecia, obesity, dementia, and cardiovascular diseases (Marques et al., 2018; Tarun et al., 2020; Afzal et al., 2019; Jessie et al., 2014). Oxidative stress of brain cells causes mitochondrial dysfunction, $A \beta$ toxicity and apoptosis. These are prevented by anthocyanin as it crosses BBB and helps in treating AD (Afzal et al., 2019). Neural sphingomyelin specific phospholipase $\mathrm{C}$ activity is modified by anthocyanin that enhances intellectual function in AD. Anthocyanins with hydroxyl groups (phenols) competitively binds with amino acids in amyloid fibril forming protein and disrupts $A \beta$ aggregation by preventing $A D$ (Miho et al., 2015). Anthocyanins have poor absorption and metabolism when these are given in oral route, it exhibits low toxicity (Pan et al., 2018). Anthocyanins find interest in food, nutraceutical, cosmetic and traditional medicine preparations for its water solubility property of pigments (Marques et al., 2018).

\subsection{Ginkgo biloba}

Ginkgo biloba (family: Ginkgoaceae) is the ancient trees (also known as maidenhair tree) which is a traditional medicine herb in Chinese system. The active constituents are obtained from leaf portion and it contains flavone, glycosides, diterpene lactones, biflavones, etc. (Bradly et al., 2000; Suresh et al., 2006; Li et al., 2017). The active constituents are extracted and concentrated using acetone water, it also removes toxic substance such as ginkgolic acid (Bradly et al., 2000). It exhibits antiapoptosis, neuroprotective, anti-inflammatory, mitochondrial protection, antidepressant, antiamnestic, antioxidant, CNS stimulant (Suresh et al., 2006; Li et al., 2017; Shi et al., 2010). Ginkgo biloba enhances neurotransmission, neuroplasticity and protects toxic amyloid beta proteins (Bader $e t$ $a l ., 2018)$. Hydrogen peroxide and amyloid beta peptide causes oxidative damage in brain cells. This is reversed by Ginkgo biloba by suppressing the activation of astrocytes and microglia (Zhang $e t$ al., 2018). Oral administration of ginkgo biloba is greatly metabolised by microorganisms present in GIT, thus decreasing the bioavailability of drugs, bioavailability is increased by individually binding the extract to phosphatidylcholine (Suresh et al., 2006). Usually, Ginkgo biloba does not cross BBB in normal physiological conditions but in case of ageing and $\mathrm{AD}$, it crosses $\mathrm{BBB}$ effectively and restores cognitive functions (Shi et al., 2010). $120 \mathrm{mg}$ /day ginkgo biloba improves dementia in $\mathrm{AD}$ and greater dose does not cause any toxicity and effect (Solomon et al., 2002).

\subsection{Glycitein}

Glycitein is a minor isoflavone (major being genistein and daidzein) obtained from the mycelia of fungus cordyceps (Bethesda et al.,
2004). It is present $5-10 \%$ of total isoflavones in soybeans and a major constituent in soy germ ranging up to $50 \%$ (Hinkaruk et al., 2012). Glycitein exhibits antioxidant, neuroprotective, estrogenic activity, hypocholesterolaemia, and prevention of cell proliferation and DNA synthesis (Gutierrez et al., 2005). Glycitein protects neuronal cells from apoptosis induced by $\mathrm{A} \beta$ aggregation and prevents $\mathrm{AD}$ (Morelli et al., 2019). It delays the $\mathrm{A} \beta$ induced paralysis and also discard the hydroxyl free radicals (Gutierrez et al., 2005). Glycitein is the only isoflavone which alters the ROS and decreases the A $\beta$ toxicity and helps in protecting from $\mathrm{AD}$. These are absorbed at the jejunum and colon of the intestine (Gutierrez et al., 2005; Hinkaruk et al., 2012). The bioavailability of the glycitein in the body is very low compared to other isoflavones (Hinkaruk et al., 2012). Glycetein has a lower toxicity in normal cells but has higher effect on cancer cells (Zang et al., 2019).

\section{Future aspects}

The demand for the use of flavonoid has increased in past one decade. Integrative techniques are required for the use of flavonoid more widely in clinical use (Kay et al., 2010). Although, at present only $1 \mathrm{~g} /$ day is consumed through naturally available vegetables and fruits. This dose can be increased by improving the study of structure of flavonoids in vivo by inducing oxidative damage (Panche et al., 2016).

\section{Conclusion}

In many fields, traditional medicine knowledge offers intrusting leads for pharmacological research. In this review, we have compiled data on a large number of flavonoids used as traditional medicine against AD. Many of these species have also displayed activity in bioassay matching their traditional use. Based on this observation, future extensive investigations on those particular species can be targeted to identify the compounds responsible for the observed bioactivities as well as to unravel their MOA. It was observed that natural flavonoids had shown a better effect in most the dementia including $\mathrm{AD}$. We hope that findings compiled in these review will contribute to the successful usage of ethnomedical knowledge of medicinal plants and their bioactive nature.

\section{Acknowledgments}

We would like to thanks Principal and Management of Krupanidhi College of Pharmacy, Bangalore for their support and encouragement.

\section{Conflict of interest}

The authors declare no conflicts of interest relevant to this article.

\section{References}

Abarikwu, S.O.; Njoku, R.C.; Lawrence, C.J.; Charles, I.A. and Ikewuchi, J.C. (2017). Rutin ameliorates oxidative stress and preserves hepatic and renal functions following exposure to cadmium and ethanol. Pharmaceutical Biology, 55(1):2161-2169.

Adaze, B.E.; William, H.; Donavon, C.H. and Soraya, B.O.E.E. (2018). Rutin as a potent antioxidant: Implications for neuro-degenerative disorders. Oxidative Medicine and Cellular Longevity, pp:1-17.

Afzal, M.; Redha, A. and AlHasan, R. (2019). Anthocyanins potentially contribute to defence against Alzheimer's disease. Molecules, 24(23):4255-4265. 
Airoldi; Cristina; La, F.; Barbara; D'Orazio; Giuseppe; Ciaramelli; Carlott; Palmioli. and Alessandro, (2018) Flavonoids in the treatment of Alzheimer's and other neuro degenerative diseases. Current Medicinal Chemistry, 25(27):3228-3246.

Anand, D.A.V.; Arulmoli, R. and Parasuraman, S. (2016). Overviews of biological importance of quercetin: A bioactive flavonoid. Pharmacognosy Reviews, 10(20):84-89.

Angéline, G.; Jean-Philippe, B.; Raymond, B.; Caroline, T.; Marie-Christine, C.; Marie-Helene, S. and Marie-Chantal, C.L. (2005). Pharmacokinetics and metabolism of apigenin in female and male rats after a single oral administration. Drug Metabolism and Disposition, 33(1):49-54.

Annoni, F.; Boccasanta, P.; Chiurazzi, D.; Mozzi, E. and Oberhauser, V. (1986). Trattamentode is in to miacutidell amalattiae morroidaria con O(beta-idrossietil)-rutosidea ad altedosi per via orale [Treatment of acute symptoms of hemorrhoid disease with high-dose oral $\mathrm{O}$ (beta-hydroxyethyl)-rutosides]. Minerva Medica,77(37):16631668

Bader, B.M.; Jügelt, K.; Schultz, L. and Schroeder, O.H. (2018). Ginkgo biloba L. (Ginkgoaceae) leaf extract medications from different providers exhibit differential functional effects on mouse frontal cortex neuronal networks. Frontiers in Pharmacology, 9:848.

Baiping, R.; Yonglan, L.; Yanxian, Z.; Yongqing, C.; Xiyog, G.; Yung, C.; Lijian, X. and Jie Z. (2018). Genistein: A dual inhibitor of both amyloid $\beta$ and human islet amylin peptides. ACS Chemical Neuroscience, 9(5): $1215-1224$.

Balez, R.; Steiner, N.; Engel, M.; Sonia, S.M.; Jeremy, S.L.; Yizhen, w.; Dadong, W.; Pascal, V.; Perminder, S. and Lezanne, O. (2016). Neuroprotective effects of apigenin against inflammation, neuronal excitability and apoptosis in an induced pluripotent stem cell model of Alzheimer's disease. Scientific Reports, 6:310-450.

Bang, S.H.; Hyun, Y.J.; Shim, J.; Hong, S.W.and Kim, D.H. (2015). Metabolism of rutin and poncirin by human intestinal microbiota and cloning of their metabolizing $\alpha$-L-rhamnosidase from bifidobacteriumdentium. Jornal of Microbiol. Biotechnology, 25:18-25.

Barve, A.; Chen, C.; Hebbar, V.; Desiderio, J.; Saw, C.L. and Kong, A.N. (2009). Metabolism, oral bioavailability and pharmacokinetics of chemopreventive kaempferol in rats. Biopharmaceutics and Drug Disposition, 30(7):356-365.

Bethesda. NCBI-National Center for Biotechnology Information. (2004) Glycitein. CID 5317750,2013.

Bradly, P.J. and Warren, S.B. (2000). Ginkgo biloba: A living fossil. The American Journal of Medicine, 108:341-342.

Chan, T.; Li, Z.; Zheng, J.; Cheung, F.S.G.; Zhu, L. and Zhou, F. (2013). Inhibitory effects of apigenin and kaempferol on the essential solute carrier transporters. World Journal of Pharmacology, 2(4):115-121.

Chen, A.Y. and Chen, Y.C. (2013). A review of the dietary flavonoid, kaempferol on human health and cancer chemoprevention. Food Chemistry, 138(4):2099-2107.

Chen, R.; Lin, J.; Hong, J.; Han, D.; Zhang, A.D.; Lan, R.; Fu, L.; Wu, Z.; Lin, J.; Zhang, W.; Wang, Z.; Chen, W.; Chen, C. and Zhang, H. (2014). Potential toxicity of quercetin: The repression of mitochondrial copy number via decreased POLG expression and excessive TFAM expression in irradiated murine bone marrow. Toxicology Reports, 1:450-458.

Choudhury; Amarendranath; Chakraborty; Indrajeet; Banerjee; Tuhin; Vana; Dhilleswara; Adapa. and Dattatreya. (2017). Efficacy of morin as a potential therapeutic phytocomponent: Insights into the mechanism of action. International Journal of Contemporary Medical Research, 6:175-194.
Constantine, G.L.; Maria, C.C.; Michael, R.J.; Ara, S.K.; Paula, T.; Joan, A.; Jesse, C.; Robert, B. and David, S.M. (2011). Neuropsychiatric symptoms in Alzheimer's disease. Alzheimer's and Dementia, 7(5):532-539.

Duan, X.; Li, Y.; Xu, F. and Ding, H. (2021). Study on the neuroprotective effects of genistein on Alzheimer's disease. Brain and Behaviour, 11(5): $1-6$.

Elena, A.; Maria, V.S.G.; Asier, R.; Fabio, C.; Carolina, O.S.; Tania, Q.L.; Estibaliz, C.Z.; Santiago, S.D. and Carlos, M. (2018). Mangiferin and morin attenuate oxidative stress, mitochondrial dysfunction, and neuro cytotoxicity, induced by amyloid beta oligomers. Oxidative Medicine and Cellular Longevity, 1-13.

Elena, A.K.;Lyudmila, A.T.; Carmina, M.; George E.B.;Gjumrakch, A. and Kaminsky, Y.G. (2018). Metabolic abnormalities of erythrocytes as a risk factor for Alzheimer's disease. Frontiers in Neuroscience, 11:728-735.

Epis, R.; Marcello, E.; Gardoni, F. and Di, L.M. (2012). Alpha, beta-and gammasecretases in Alzheimer's disease. Frontiers in Bioscience, Scholar Edition, 4:1126-1150.

Francesca, M.; Alina, S.; Bengt, W.; Patrizia, M. and Miia, K. (2010). Alzheimer's disease: Clinical trials and drug development. The Lancet Neurology, 9(7):702-716.

Gargari, S.A. and Barzegar, A. (2020). Simulations on the dual effects of flavonoids as suppressors of A $\beta 42$ fibrillogenesis and destabilizers of mature fibrils. Scientific Reports, 10:16636.

Geetha, T.; Malhotra, V.; Chopra, K. and Kaur, J. (2005). Antimutagenic and antioxidant/prooxidant activity of quercetin. Indian Journal of Experimental Biology, 43(1):61-67.

Gutierrez-Zepeda,A.; Santell, R.; Wu, Z.; Brown, A.; Wu, Y.J.; Khan, I.; Link, C.D.; Zhao,B. and Luo, Y. (2005). Soy isoflavone glycitein protects against beta amyloid-induced toxicity and oxidative stress in transgenic caenorhabditis elegans. BMC Neuroscience, 6:54-60.

Hong, C.; Guo, H.; Chen, S.; Zhang, X.; Yang, Y.; Huang, K.; Tian, Z.Y.; Luo, W. and Chen, Y. (2019). Synthesis and biological evaluation of genistein-Oalkylamine derivatives as potential multifunctional anti-Alzheimer agents. Chemical Biology and Drug Design, 93:188-200.

Isha, S.; Priyanka, P.; Mohammad, L.M. and Mordhwaj, S.P. (2015). Flavonoidbased therapies in the early management of neurodegenerative diseases. Advances in Nutrition, 6:64-72.

Jessié,M.G.; Fabiano, B.C.; Maria, R.C.; Schetinger; Patrícia, M.; Paula, A.; Marília R.; Maribel, A.R.; Roberta, S.; Cassia, R.D.S.; Giana, D.P.C.; Julia, G.F.; Cristiane, S.; Vera, M.M. and Cinthia, M.M. (2014). Anthocyanins restore behavioural and biochemical changes caused by streptozotocininduced sporadic dementia of Alzheimer'stype. Life Sciences, 96(12):7-17.

Judy, T.T.Z.; Roy, C.Y.Choi.; Glanice, K.Y.C.; Anna, W.H.C.; Qiu, T.G.; Jun, L.; Zhi, Y.J.; Tina, T.X.D. and Karl, W.K.T. (2007).Flavonoids possess neuroprotective effects on cultured pheochromocytoma PC12 cells: A comparison of different flavonoids in activating estrogenic effect and in preventing $\beta$-amyloid-induced cell death. Journal of Agricultural and Food Chemistry, 55(6):2438-2445.

Justin, A.L. and David, R.B. (2010). Destabilizing Alzheimer'sA $\beta 42$ protofibrils with morin: Mechanistic insights from molecular dynamics simulations. Biochemistry, 49(18):3935-3946.

Kay, C. (2010). The future of flavonoid research. British Journal of Nutrition, 104(S3):91-95. 
Khan, H.; Ullah, H.; Aschner, M.; Cheang, W.S. and Akkol, E.K. (2020). Neuroprotective effects of quercetin in Alzheimer's disease. Biomolecules, 10(1):59.

Khoo, H.E.; Azlan, A.; Tang, S.T. and Lim, S.M. (2017). Anthocyanidins and anthocyanins: Coloured pigments as food, pharmaceutical ingredients, and the potential health benefits. Food and Nutrition Research, 61(1):1361779.

Kloska, A.; Narajczyk, M.; Jakóbkiewicz-Banecka, J.; Grynkie-wicz, G.; Szeja, W.; Gabig-Ciminska, W. and Wegrzyn, G. (2012). Synthetic genistein derivatives as modulators of glyco-saminoglycan storage. Journal of Translational Medicine, 10:153.

Kouhestani, S.; Jafari, A. and Babaei, P. (2018). Kaempferol attenuates cognitive deficit via regulating oxidative stress and neuroinflammation in an ovariectomized rat model of sporadic dementia. Neural Regeneration Research, 13(10):1827-1832.

Li, S.; Li, J.; Dai, W.; Zhang, Q.; Feng, J.; Wu, Li.; Liu, T.; Yu,Q.; Xu,s. and Wang, W. (2017). Genistein suppresses aerobic glycolysis and induces hepatocellular carcinoma cell death. British Journal of Cancer, 117: $1518-1528$

Li, Y.; Xiong, Y.; Zhang, H.; Li, J.; Wang, D.; Chen, W.; Yuan, X.; Su, Q.; Li, W. and Huang, H. (2017). Ginkgo biloba extract EGb761 attenuates brain death-induced renal injury by inhibiting pro-inflammatory cytokines and the SAPK and JAK-STAT signalings. Scientific Report, 7:45192.

Li, Y.; Yao, J.; Han, C.; Yang, J.; Chaudhry, M. T.; Wang, S.; Liu, H. and Yin, Y. (2016) Quercetin, inflammation and immunity. Nutrients, 8(3):167.

Mahendra, V.P.; Yogendra Prasad, K.; Ganesan, P. and Ravi, K.(2020). Mechanism of rutin mediated inhibition of insulin amyloid formation and protection of neuro-2a cells from fibril-induced apoptosis. Molecular Biology Report, 47:2811-2820.

Maher and Pamela (2020). Preventing and treating neurological disorder with the flavonol fisetin. Brain Plasticity, 6(2):155-166.

Manorma, S. (2018). Study on potential antioxidant activity of fisetin against oxidative stress in vivo. Fisetin : A potent natural compound with a strong safety profile. JUVICELL.

Marques, C.; Fernandes, I.; Meireles, M.; Ana, F.; Jermery, P.E.S.; Mateus, N. and Calhau, C. (2018). Gut microbiota modulation accounts for the neuroprotective properties of anthocyanins. Scientific Reports, 8:11341.

Meghana, K.; Bidya, D.S.; Jerald, M.K.; Madhusudana, K. and Amrita, K. (2016) Fisetinprotects liver from binge alcohol-induced toxicity by mechanisms including inhibition of matrix metallo proteinases (MMPs) and oxidative stress. Journal of Functional Foods, 22:588601 .

Michal, A.; Iftach, Y. and Beka, S. (2005). Inhibition of amyloid precursor protein processing by $\beta$-secretase through site-directed antibodies. Proceedings of the National Academy of Sciences, 102(21):77187723.

Miho, Y.Y.; Kazuyuki, U.; Yasuhiro, W.; Tadashi, A.; Mami, N.; Hikari, I.; Kunihiro, H.; Tomohiro, M.; Saori, K.; Kenji, N. and Yasushi, K. (2015). Anthocyanin suppresses the toxicity of $A \beta$ deposits through diversion of molecular forms in in vitro and in vivo models of Alzheimer's disease. An International Journal of Nutrition, Diet and Nerves System, 19(1):32-42.
Minqian, W.; Jenni, F.; LinShu, L. and Kit, Y. (2019). A review on flavonoid Apigenin: Dietary Intake, ADME, antimicrobial effects, and interactions with human gut microbiota. Bio. Med. Research International, pp:1-18.

Morelli, S.; Piscioneri, A.; Curcio, E.; Salerno, S.; Chien-Chung, C. and Bartolo, L.D (2019). Membrane bioreactor for investigation of neuro degeneration. Materials Science and Engineering, 103:1-44.

Mostafa, N.M. (2019). Rutin: A potential therapeutic agent for Alzheimer disease. Pharmaceutica Analytica Acta, 10:615.

Naeimi, A.F. and Mohammad A. (2015). Antioxidant properties of the flavonoid fisetin: An updated review of in vivo and in vitro studies. Trends in Food Science and technology, 70:34-44.

Naghma, K.; Deeba, N.S.; Nihal, A. and Hasan, M. (2013). Fisetin: A dietary anti-oxidant for health promotion. Antioxidants and Redox Signalling, 19(2):151-162.

NCBI-National Center for Biotechnology Information. (2021). Genistein CID 5280961 .

Olajide, O.A. and Sarker, S.D. (2020). Alzheimer's disease: Natural products as inhibitors of neuro inflammation. Inflammopharmacology, 28:1439-1455.

Pan, Z.; Cui, M.; Dai, G.; Yuan, T.; Li, Y.; Ji, T. and Pan, Y. (2018). Protective effect of anthocyanin on neurovascular unit in cerebral ischemia/ reperfusion injury in rats. Frontiers in Neuroscience, 12:947.

Panche, A.; Diwan, A. and Chandra, S. (2016). Flavonoids: An overview. Journal of Nutritional Science, 5: E47.

Perry, E.K. (1980). The cholinergic system in old age and Alzheimer's disease. Age and Ageing, 9(1):1-8.

Qadeer, K. P. and Shahabuddin, M. (2014). Synthesis of Cr (III)-morin complex: characterization and antioxidant Study. The Scientific World Journal, pp:1-8.

Raju, D. (2018). Molecular docking and binding free energy analysis of rutin and apigetrin as galectin-1 inhibitors SDRP. Journal of Computational Chemistry and Molecular Modelling, 2(2):162-171.

Rashid, M.I.; Fareed, M.I.; Rashid, H.; Aziz, H.; Ehsan, N.; Khalid, S.; Ghaffar, I.; Ali, R.;Gul, A. and Hakeem, K.R. (2019). Flavonoids and their biological secrets. Plant and Human Health, 2:579-605.

Ren, J.; Lu, Y.; Qian, Y.; Chen, B.; Wu, T. and Ji, G. (2019). Recent progress regarding kaempferol for the treatment of various diseases (Review). Experimental and Therapeutic Medicine, 18:2759-2776.

Robert, J.N.; Els, V.N.; Danny, E.C.V.H.; Petra, G.B.; Klaske, V.N. and Paul,A.M.V.L. (2001). Flavonoids: A review of probable mechanisms of action and potential applications. The American Journal of Clinical Nutrition, 74(4):418-425

Roxona, B.D.A.T.; Diniz, T.C.; Costa, P.T.C.; de Oliveira, J.R.G.; Gama, E.S.M.; de Lavor, É.M.; Fernandes, A.; de Oliveira, A.P.; de Almeida R.F.; da Silva, A.; Cavalcante, T.; Quintans, J.L.J. and da Silva, A.J. (2018). Flavonoids as therapeutic agents in Alzheimer's and Parkinson's diseases: A systematic review of preclinical evidence. Oxidative Medicine and Cellular Longevity, 7043213:1-21.

Rui-Yuan, P.; Jun, M.; Xiang-Xi, K.; Xiao-Feng, W.; Shuo-Shou, L.; Xiao-Long, Q.; Yu-Han, Y.; Jinbo, C.; Qingsong, L.; Wanzhu, J.; Tan, C.H. and Yuan,Z. (2019). Sodium rutin ameliorates Alzheimer'sdisease-like pathology by enhancing microglial amyloid- $\beta$ clearance. Science Advances, 5(2): $1-15$. 
Shashank, K. and Abhay, K.P. (2013). Chemistry and biological activities of flavonoids: An overview. The Scientific World Journal, 162750:116.

Sharma, D.; Singh, M.; Kumar, P.; Vikram, V. and Mishra, N. (2017). Developmen and characterization of morin hydrate loaded microemulsion for the management of Alzheimer's disease. Artificial Cells, Nanomedicine, and Biotechnology, 45(8):1620-1630.

Shi, C.; Liu, J.; Wu, F. and Yew, D.T. (2010). Ginkgo biloba extract in Alzheimer's disease: From action mechanisms to medical practice. International Journal of Molecular Sciences, 11(1):107-123.

Shifeng, X.; Yafei,L.; Qiuping, W.; Jiaying, Y.; Jierui, C.; Suyue, Z; David, E.; Qiulong, T. and Chengchen, W. (2021). Fisetin inhibits Tau aggregation by interacting with the protein and preventing the formation of $\beta$ strands. International Journal of Biological Macromolecules, 178:381-393

Simunkova, M.; Barbierikova, Z.; Jomova, K.; Hudecova, L.; Lauro, P.; Alwasel, S.H.; Alhazza, I.; Rhodes, C.J. and Valko, M. (2021). Antioxidant vs. prooxidant properties of the flavonoid, kaempferol, in the presence of $\mathrm{Cu}$ (II) ions: A ROS-scavenging activity, fenton reaction and DNA damage study. International Journal of Molecular Science, 22(4):16-19.

Simunkova, M.; Alwasel, S.H.; Alhazza, I.M.; Jomova, K.; Kollar, V.; Rusko, M. and Valko, M. (2019). Management of oxidative stress and other pathologies in Alzheimer'sdisease. Archives of Toxicology, 93:2491-2513.

Solomon, P.R.; Adams, F.; Silver, A.; Zimmer, J. and DeVeaux, R. (2002). Ginkgo for memory enhancement: A randomized controlled trial. Jounal of American Medical Association, 288(7):835-840

Suresh, R.N.; Vinaya, W.P. and Vandana, S.P. (2006). Neurophar-macological evaluation of Ginkgo biloba phytosomes in rodents. Phytotherapy Research, 20:901-905.

Svitlana, S.; Marlène, D.; Valérie, L.; Allison, C.; Amandine, M.; Philppe, C. Sebasten, V. and Xavier, N. (2012). Bioavailability of glycitein relatively to other soy isoflavones in Caucasian men. Food Chemistry, 135:1104-1111.

Tarun, B.; Gopal, S.; Philippe, J.; Aseesh, P.; Lalit, G.; Sudipta, R.; Indra, D.B.; Petras, R.V.; Milen, I.G.; Christophe, C. and Zisheng, L. (2020). Anthocyanins, multi-functional natural products of industrial relevance: Recent Biotechnological Advances, 43:0734-9750.

Uddin, M.S. and Kabir, M.T. (2019). Emerging signal regulating potential of genistein against Alzheimer's disease: A promising molecule of interest. Frontiers in Cell and Developmental Biology, 7:197-202.
Venigalla, M.; Gyengesi, E. and Münch, G. (2015). Curcumin and apigenin novel and promising therapeutics against chronic neuroinflammation in Alzheimer's disease. Neural Regeneration Research, 10(8):1181-1185.

Wang, T.H.; Wang, S.Y.; Wang, X.D.; Jiang, H Q.; Yang, Y.Q.; Wang, Y.; Cheng, J.L.; Zhang, C.T.; Liang, W.W. and Feng, H.L. (2018). Fisetin exerts antioxidant and neuroprotective effects in multiple mutant hSOD1 models of amyotrophic lateral sclerosis by activating ERK. Neuroscience, 379:152-166.

Wen-bin,H.; Kazuho, A. and Tatsuhiro, A. (2018). Oral administration of fisetin promotes the induction of hippocampal long-term potentiation in vivo. Journal of Pharmacological Sciences, 136(1):42-45.

Xinjun, Y.; Yicai, L. and Xiaohua, M. (2020). Effect of quercetin on PC12 Alzheimer's disease cell model induced by A $\beta 25-35$ and its mechanism based on sirtuin1/Nrf2/HO-1 pathway. Bio. Med. Research International, 1-10.

Yu, K.C.; Kwan, P.; Cheung, S.; Ho, A. and Baum, L. (2018). Effects of resveratrol and morin on insoluble Tau-in-Tau transgenic mice. Translational Neuroscience, 9:54-60.

Zang, Y.Q.; Feng, Y.Y.; Luo, Y.H.; Zhai, Y.Q.; Ju, X.Y.; Feng, Y.C.; Wang, J.R.; Yu, C.Q. and Jin, C.H. (2019).Glycitein induces reactive oxygen speciesdependent apoptosis and G0/G1 cell cycle arrest through the MAPK/ STAT3/NF- $\kappa$ B pathway in human gastric cancer cells. Drug Development Research, 80(5):573-584

Zhang, N.; Xu, H.; Wang, Y.; Yao, Y.; Liu, G.; Lei, X.; Sun, H.; Wu, X. and Li, J. (2021). Protective mechanism of kaempferol against A $325-35$-mediated apoptosis of pheochromocytoma (PC-12) cells through the ER/ ERK/MAPK signalling pathway. Archives of Medical Science, 17(2):406-416.

Zhang, Y.; Liu, J.; Yang, B.; Zheng, Y.; Mingjiang, Y.; Sun, M.; Xu, L.; Lin, C.; Chang, D. and Tian, F. (2018). Ginkgo biloba extract inhibits astrocytic lipocalin-2 expression and alleviates neuroinflammatory injury via the JAK2/STAT3 pathway after ischemic brain stroke, role of natural compounds on immunomodulation and cardiovascular homeostasis. Frontiers in Pharmacology, 9:1-11.

Zhao, L.; Wang, J.L.; Liu, R.; Li, X.X.; Li, J.F. and Zhang, L. (2013). Neuroprotective, anti-amyloidogenic and neurotrophic effects of apigenin in an Alzheimer'sdisease mouse model. Molecules (Basel, Switzerland), 18(8):9949-9965. 